\title{
Lugano classification: response evaluation criteria for positron emission tomography/ computed tomography in lymphoma follow-up
}

\author{
Samar R. Ragheb*, Amir L. Louka and Sherine M. Sharara
}

\begin{abstract}
Background: The purpose of this study is to assess the role of 18 fluorodeoxyglucose positron emission tomography/computed tomography $\left({ }^{18} \mathrm{FDG}\right.$ PET-CT) in the follow-up of patients with lymphoma after finishing therapy.

Results: This study included 42 lymphomas (25 non-Hodgkin's lymphoma and 17 Hodgkin's lymphoma); patients ranging in age from 18 to 70 years were examined by ${ }^{18}$ FDG PET-CT after therapy and analyzed retrospectively. Confirmatory biopsy was mandatory in cases of suspected disease recurrence and follow-up in cases of complete metabolic response. Positron emission tomography/computed tomography in assessment of lymphoma treatment response reveals significant statistical significance $(P<0.05)$. It shows $100 \%$ sensitivity, $92.8 \%$ specificity, and $95.2 \%$ accuracy in the prediction of response.
\end{abstract}

Conclusion: Positron emission tomography/computed tomography plays an important role in detection of response to treatment of lymphoma after finishing therapy.

Keywords: Lymphoma, PET, CT, Lugano classification

\section{Background}

Fluorodeoxyglucose positron emission tomography/ computerized tomography $\left({ }^{18} \mathrm{FDG} \mathrm{PET} / \mathrm{CT}\right)$ [1] is a powerful imaging modality in the field of oncology since it detects the enhanced glycometabolic activity of neoplastic cells, with the ability to define tumor burden and involved organs. Its role in managing lymphoma patients has grown progressively, and its use is now often recommended in [2-5], monitoring the therapy [6-15], and its modeling [16].

So far, only few studies in literature focused on the role of ${ }^{18}$ FDG PET during follow-up, especially its capability to detect relapse earlier with respect to CT or ultrasound imaging issue. The conclusions

\footnotetext{
*Correspondence: doc_mina2004@yahoo.com

Faculty of Medicine, Ain Shams University, Cairo, Egypt
}

are not definite, raising the concern about sensitivity and specificity of the technique in this setting and the need of histological verification of ${ }^{18} \mathrm{FDG}$ PET positivity [1]. In aggressive lymphomas, earlier detection is important since a timely salvage treatment is related to better outcome. Thus, analyzing ${ }^{18}$ FDG PET positivity patterns during follow-up to distinguish patients who should be referred to an immediate surgical biopsy to start further treatment from patients who could be managed with a more conservative observational approach that could be repeating imaging after 2 or 3 months to confirm or avoid biopsy [2, 4].

The clinical response based on PET-CT scans was defined in 2007 by the International Harmonization

(c) The Author(s). 2020 Open Access This article is licensed under a Creative Commons Attribution 4.0 International License, which permits use, sharing, adaptation, distribution and reproduction in any medium or format, as long as you give appropriate credit to the original author(s) and the source, provide a link to the Creative Commons licence, and indicate if changes were made. The images or other third party material in this article are included in the article's Creative Commons licence, unless indicated otherwise in a credit line to the material. If material is not included in the article's Creative Commons licence and your intended use is not permitted by statutory regulation or exceeds the permitted use, you will need to obtain permission directly from the copyright holder. To view a copy of this licence, visit http://creativecommons.org/licenses/by/4.0/. 
Project criteria [3, 4], and interpretation of PET was subsequently standardized by the proposal of the Deauville criteria for grading the degree of FDG avidity in comparison to the mediastinal blood pool and liver [5]. The Lugano classification, published in 2014, aimed to simplify and standardize baseline and response assessment and confirm the role for FDG PET-CT in lymphoma. Current study will assess the role of functional imaging with FDG PET$\mathrm{CT}$ in lymphoma at the end of treatment and follow-up [17].

The most recent system proposed for response assessment, known as the Lugano classification [17], applies to both Hodgkin and non-Hodgkin lymphoma. The use of standardized criteria for response assessment is important for making accurate treatment decisions and for determining the direction of further research. This review provides an overview of the updated PET-CT response criteria to familiarize the radiologist with the most important and clinically relevant aspects of lymphoma imaging $[15,16]$.

The Lugano classification proposes new definitions relevant to imaging in lymphoma: for splenomegaly, vertical length of spleen greater than $13 \mathrm{~cm}$; for measurable adenopathy, nodal long-axis diameter greater than $1.5 \mathrm{~cm}$ (a unidimensional measurement) [5-10].

Response at FDG PET/CT is graded on the five-point scale and categorized as complete metabolic response (scores 1, 2, 3), partial metabolic response (score 4 or 5 with reduced FDG uptake), no metabolic response (score 4 or 5 with no significant change in FDG uptake), or progressive metabolic disease (score 4 or 5 with increased FDG uptake or new lesions compared to previous scan) $[3,4]$.

\section{Methods}

Current study is a retrospective study comprised of 42 patients, referred from the oncology department, ranging in age from 18 to 70 years. The study was conducted during the period from July 2016 till January 2018 and approved by the local research ethical committee at our university.

Inclusion criteria included patient affected with lymphoma and underwent surgical resection or chemotherapy or radiotherapy, in which imaging was done before and after 6 months from treatment, with no age or sex predilection in patient selection. On the other hand, pregnant females, patients with history of previous hypersensitivity reaction to contrast material, and patients with renal failure were excluded from the study. A detailed history taking and informed consent were obtained from all patients.

\section{Patient's preparation}

Participants avoided strenuous exercise for $24 \mathrm{~h}$ and fasted for at least $4 \mathrm{~h}$ before examination. Blood glucose level should be below $200 \mathrm{mg} / \mathrm{dl}$ in which diabetic patients relevant considerations before the study include restrictions of diet and activity and management of blood glucose levels in diabetic patients, as well as an awareness of the effect of medications and environmental conditions. The patient was asked to void before scan.

\section{PET-CT technique}

A dedicated PET scanner (DST PET/CT; Discovery ST PET-CT, General Electric Medical Systems, Milwaukee, WI, USA) was used, and the radiopharmaceutical used was 18F-FDG. All examinations were carried out using two integrated PET-CT scanners (Ingenuity TF 128; Philips Healthcare, Cleveland, OH, USA) $1 \mathrm{~h}$ after intravenous administration of 7-11 $\mathrm{mCi}$ of 18F-FDG corresponding to the patient's body weight. Blood glucose level should be less than 200 at time of 18F-FDG injection, if more, no injection is done. The time of 18F-FDG injection to the scan is $45 \mathrm{~min}$.

Multidetector computed tomography diagnostic post contrast examination was taken after I.V. nonionic contrast administration for attenuation correction. The contrast agent iopromide (Ultravist) (300 $\mathrm{mg}$ of iodine $/ \mathrm{ml}$ ) was used at a dose of $100-120 \mathrm{ml}$ corresponding to the patient's body weight with a 3$\mathrm{ml} / \mathrm{s}$ infusion rate, following the administration of $50 \mathrm{ml}$ of a normal saline chaser at a $3-\mathrm{ml} / \mathrm{s}$ infusion rate. Anatomic localization followed by PET images from the skull vault to the mid-thigh was obtained. Images of $\mathrm{CT}$ and corresponding functional PET

\begin{tabular}{|c|c|}
\hline Score & Definition \\
\hline 1 & No uptake above background \\
\hline 2 & Uptake at an initial site that is less than or equal to mediastinum \\
\hline 3 & $\begin{array}{l}\text { Uptake at an initial site that is greater than mediastinum but less } \\
\text { than or equal to liver }\end{array}$ \\
\hline 4 & $\begin{array}{l}\text { Uptake at an initial site that is moderately increased compared } \\
\text { to the liver at any site }\end{array}$ \\
\hline $5 a$ & $\begin{array}{l}\text { Uptake at an initial site that is markedly increased compared to } \\
\text { the liver }\end{array}$ \\
\hline $5 b$ & $\begin{array}{l}\text { Uptake markedly increased compared to the liver at any new site } \\
\text { that is possibly related to lymphoma }\end{array}$ \\
\hline $\mathbf{X}$ & New areas of uptake unlikely related to lymphoma \\
\hline
\end{tabular}


Table 2 Demographic data of the studied patients (No. $=42$ )

\begin{tabular}{lll}
\hline Demographic & \multicolumn{2}{l}{ All studied patients $(\boldsymbol{n}=42)$} \\
\cline { 2 - 3 } data & No. & $\%$ \\
\hline Gender & & $60 \%$ \\
Female & 25 & $40 \%$ \\
$\quad$ Male & 17 & \\
Age & & \\
$\quad$ Mean \pm SD & $40 \pm 15$ & \\
Median (range) & $37(18-70)$ &
\end{tabular}

images were taken in axial, coronal, and sagittal planes. Patient's height and weight were measured. SUV average of reference hepatic activity was measured according to the hepatic activity, and SUV was calculated according to the lean body mass.

\section{Image analysis}

Analysis of PET-CT images was performed with correlation to Deauville criteria (Table 1) [17]. We measured maximum dimensions of the enlarged lymph nodes or extranodal tissues. A lesion was considered positive if there is abnormal FDG uptake greater than surrounding tissue and not related to physiologic uptake sites (e.g., myocardium). Maximum standardized uptake values (SUV max) were then measured.

\section{Statistical analysis}

All data were collected, tabulated, and analyzed using SPSS 20.0 for windows (SPSS Inc., Chicago, IL, USA). Quantitative data were expressed as the mean \pm SD and median (range), and qualitative data were expressed as absolute frequencies (number and percentage). Percent of categorical variables was
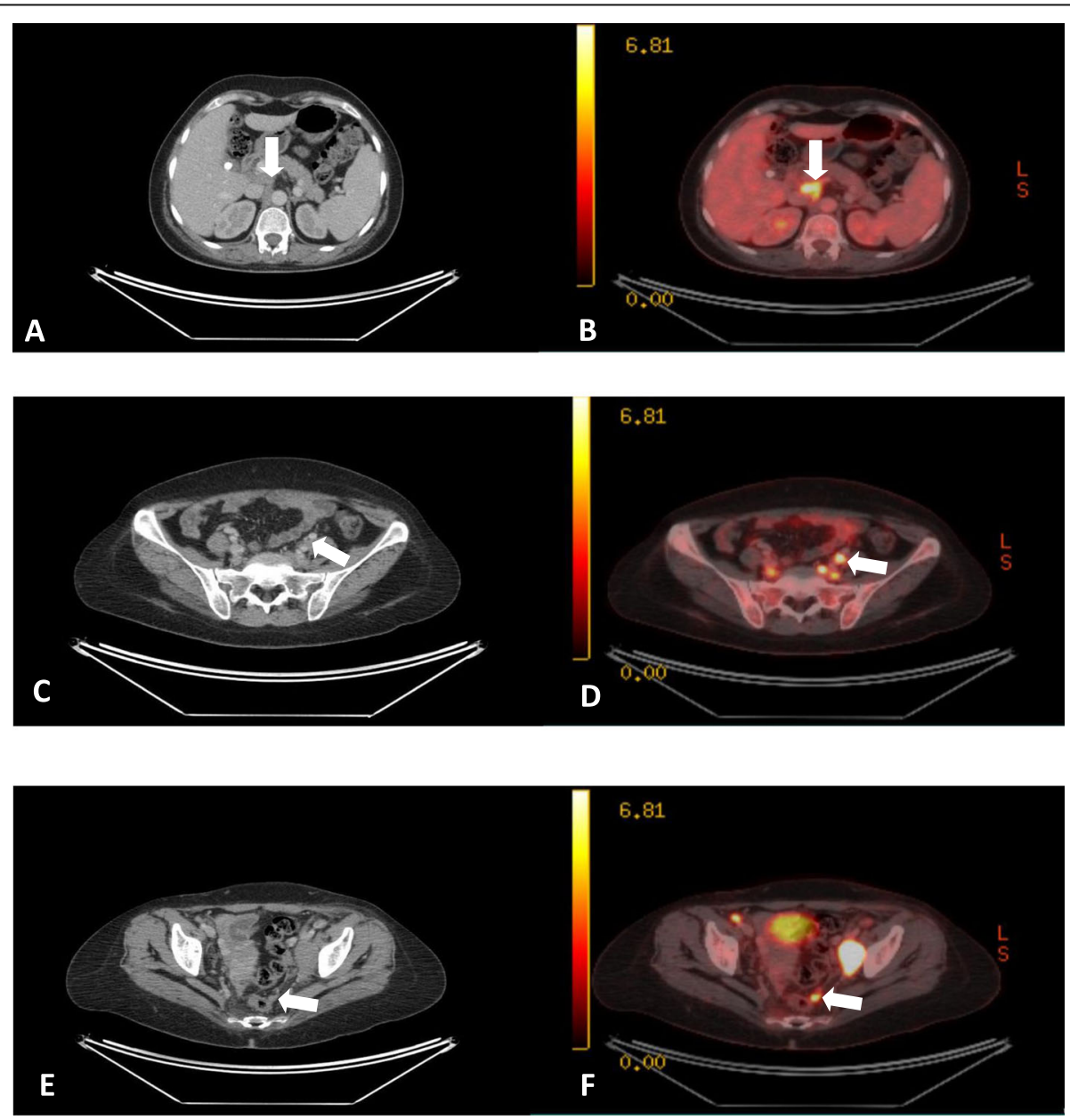

Fig. 1 Thirty-seven-year-old patient, known case of non-Hodgkin lymphoma. Multiple infradiaphragmatic metabolically active lymph nodes seen at the following sites: celiac, aortocaval, precaval ( $\mathbf{a}$ and $\mathbf{b}$ ); paraaortic, bilateral common iliac, bilateral internal (c and $\mathbf{d}$ ); and external iliac and left para rectal (e and f), with the largest in precaval measuring $23.3 \times 14.7 \mathrm{~mm}$ with SUV max 10.5, consistent with a score of 4 on the five-point scale 

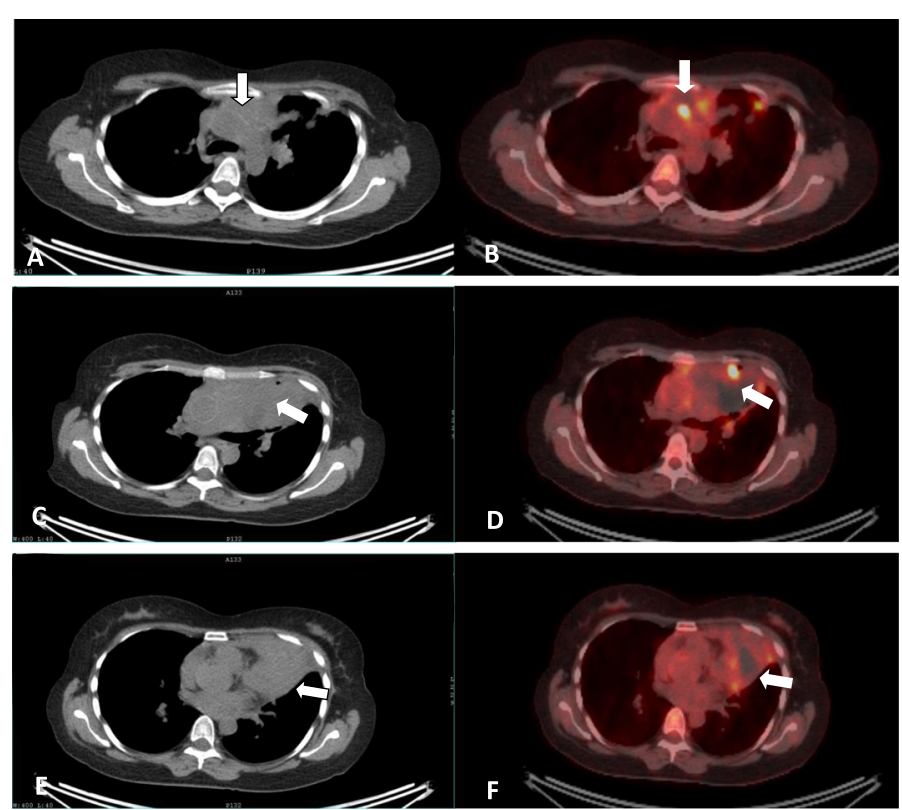

Fig. 2 Thirty-five-year-old female patient, known case of lymphoma. a-f Anterior mediastinal mass lesion comprising matted lymph nodes. This necrotic infiltrative lesion measures $8 \times 6 \times 5 \mathrm{~cm}$, showing preferential avid FDG uptake of SUV max 21.4, consistent with a score of 4 on the five-point scale
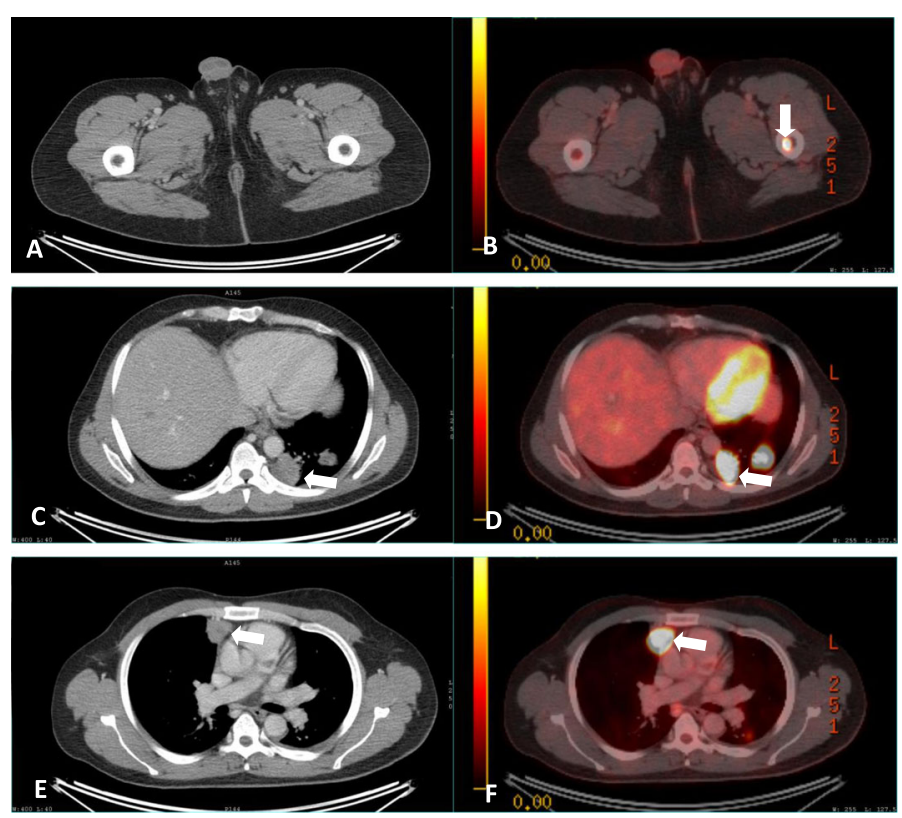

Fig. 3 Thirty-one-year-old male patient with history of NHL received CTH. Multiple variable-sized marrow infiltrative lesions largest seen at left femur (a and $\mathbf{b}$ ) with Max SUV of 25. Bilateral multiple variable-sized metabolically active nodules are seen involving lung parenchyma (c-f) in which the largest on the right side seen involving the right medial segment of middle lobe measuring $30 \times 27 \mathrm{~mm}$ and SUV max $=302$, and on the left side, the largest nodule is seen at postero-medial segment of lower lobe measuring $25 \times 29 \mathrm{~mm}$. SUV max $=24$, consistent with a score of 5 on the five-point scale 

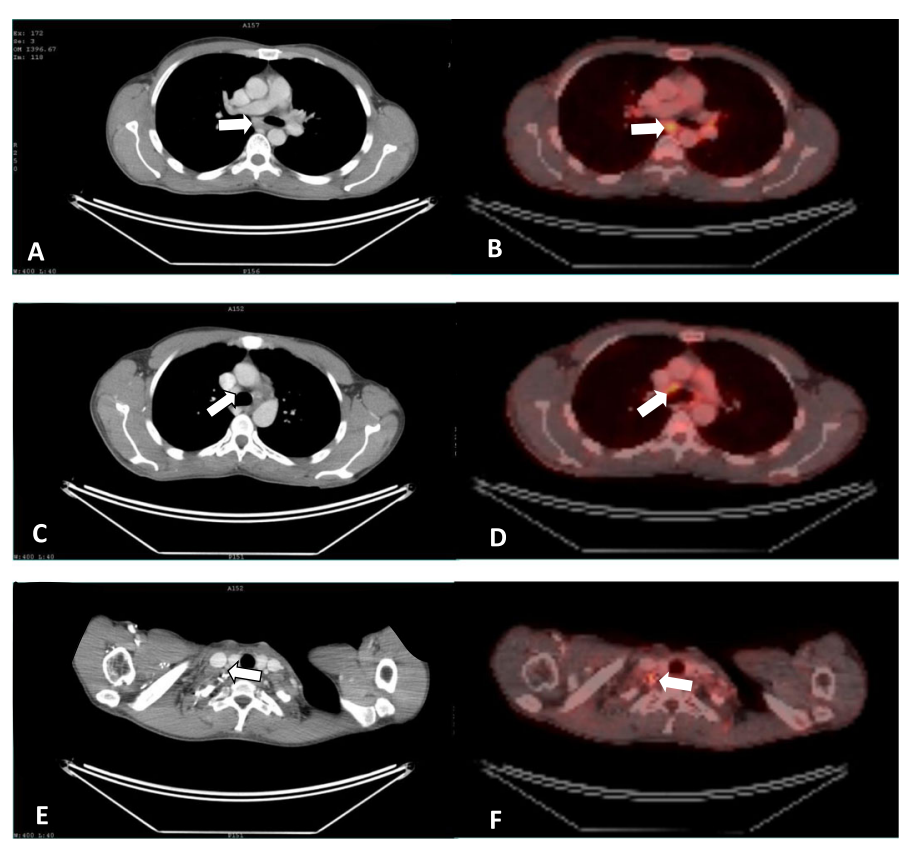

Fig. 4 Forty-two-year-old male patient, known case of Hodgkin lymphoma. Metabolically active pretracheal (a-d) and aortopulmonary LN groups, largest measures $1.4 \times 0.8 \mathrm{~cm}$ with SUV max $=7.2$ and multiple low metabolically active small retrocaval, paraaortic, and left common iliac (e and f) (likely inert lymph nodes) with SUV max 2.2, consistent with a score of 3 on the five-point scale

compared using ANOVA. All tests were two sided. $P$ value $<0.05$ was considered statistically significant $(\mathrm{S})$, and $P$ value $\geq 0.05$ was considered statistically insignificant (NS).

\section{Results}

This study included 42 patients (Table 2); their ages ranged from 18 to 70 years (mean \pm SD for age was $40 \pm$ 15). Seventeen cases had Hodgkin lymphoma (40\%); 25 cases had non-Hodgkin lymphoma (60\%). All cases were pathologically proven prior to imaging either by surgical or imaging-guided biopsy.
Regarding nodal affection, 26 cases had supradiaphragmatic LNs, 9 cases had infradiaphragmatic LNs, and 7 cases had both supradiaphragmatic and infradiaphragmatic LNs. Lymph nodes were either solitary lymph nodes (range from 1 to $3 \mathrm{~cm}$ ) or amalgamated lymph nodes (range from 5 to $25 \mathrm{~cm}$ ).

Extranodal involvement (Fig. 1) was detected in 13 cases, 10 cases with bony lesions, 2 cases with pulmonary nodules (Fig. 2), 2 cases with splenic involvement, 1 case with renal involvement, 1 case with thymic involvement, 1 case with thyroid involvement, and 1 case with subcutaneous involvement.

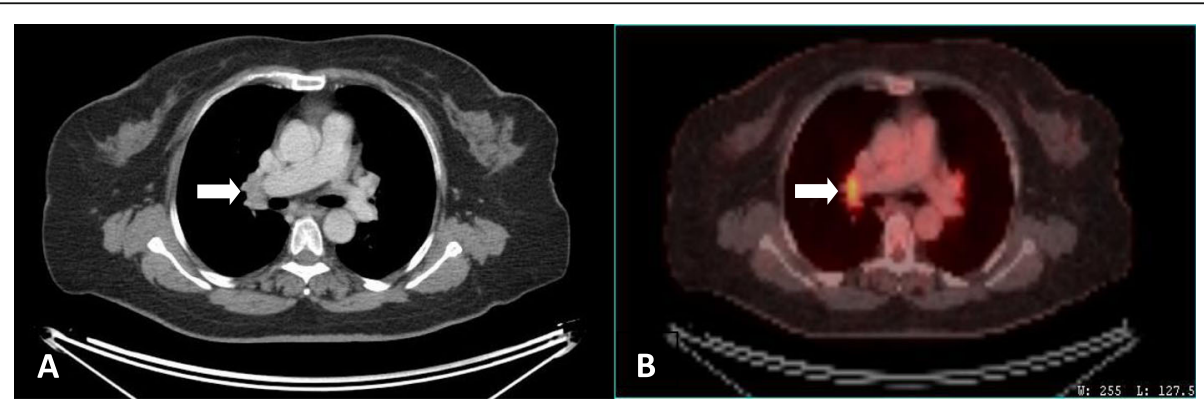

Fig. 5 Fifty-two-year-old patient presented with history of right ovarian malignant lymphoma underwent surgical resection and received CTH, for follow-up. CECT reveals enlarged bilateral hilar LNs (a). PET-CT (b) shows bilateral hilar FDG avid LNs; the largest is on the right side measuring 19 $\times 13 \mathrm{~mm}$ with SUV $\max 6.46$, consistent with a score of $5 \mathrm{~b}$ on the five-point scale 
Table 3 Treatment response of patients according to Lugano classification

\begin{tabular}{ll}
\hline Type of response & Number of patients \\
\hline Stationary & 1 \\
Progressive metabolic response & 13 \\
Partial metabolic response & 5 \\
Complete metabolic response & 23 \\
\hline
\end{tabular}

The follow-up of our cases revealed 9 cases with newly developed lesions: 7 cases developed newly nodal lesions, 1 case developed hepatic focal lesions, and 1 case developed bony lesions (Fig. 3).

In the current study, regarding the SUV max of lymph nodes before therapy ranged from 3 to 15 with mean = 7.21 , SUV max after therapy ranged from 2.4 to 25 with mean $=7.08$.

The treatment of our cases was as follows: 1 case received bone marrow transplant (BMT) and chemotherapy $(\mathrm{CTH}), 35$ cases received chemotherapy, 3 cases received chemotherapy and radiotherapy (RTH), and 3 cases received surgical resection and chemotherapy (Figs. 4 and 5).

According to Lugano classification, PET-CT (Table 3 ) showed 1 patient with stationary disease, 13 patients with progressive metabolic response, 5 patients with partial metabolic response, and 23 patients with complete metabolic response (Figs. 6 and 7).

Grading of lymphoma FDG avidity on PET-CT according to Deauville criteria was as shown in Table 4.

In the current study, 18 cases out of 42 patients which proved to have disease progression either (partial or progressive metabolic response) by the PET/ $\mathrm{CT}$, the biopsy results of 16 out of the 18 cases proved to be positive, while 2 cases proved to be negative by biopsy.

Comparison of PET-CT and biopsy results in assessment of treatment response reveals significant statistical difference $(P<0.05)$. Hence, PET-CT achieved sensitivity $=100 \%$, specificity $=92.8 \%$, accuracy $=95 \%$, positive predictive value $=88.9 \%$, and negative predictive value $=100 \%$.

\section{Discussion}

Lymphoma is considered the most common primary malignancy of hematopoietic origin [18]. Positron emission tomography (PET) using $18 \mathrm{~F}$ FDG integrated with computed tomography (CT) (PET/CT) has become widely used in the diagnosing, staging, and evaluation of therapy response in lymphomas [19].

The Lugano classification [20] stated that bone marrow biopsy may be obviated in patients with Hodgkin lymphoma and aggressive non-Hodgkin lymphoma if FDG PET-CT is clearly positive for marrow involvement. Bone marrow biopsy may remain necessary in other patients depending on the clinical question and lymphoma histology. In the spleen, focal lesions with FDG avidity above background in typically avid lymphomas are strongly suggestive of splenic lymphoma, as is diffuse FDG avidity of the pretreatment spleen greater than that of the liver. The uptake FDG by gastrointestinal tract lymphoma is variable but may be detected on FDG PET-CT images in 60 (for mucosa associated lymphoma [21]) to $100 \%$ (for large cell lymphoma) of cases.

In current study, we investigated the role of PET-CT scan in the follow-up of treatment response in 42 patients in which 17 cases (40.4\%) were $\mathrm{HL}$ and 25 cases $(59.6 \%)$ were NHL. The most important result in this study was 23 cases showed CMR and only case had stationary MR. Also, out of 42 cases, 13 showed progressive MR and 5 cases showed partial MR. A biopsy was taken from the 18 cases in which 16 out of 18 were positive and the other 2 were negative. So, in 42 patients with lymphoma, PET attained 100\% sensitivity, $92.8 \%$ specificity, and $95.2 \%$ accuracy in the prediction of response.

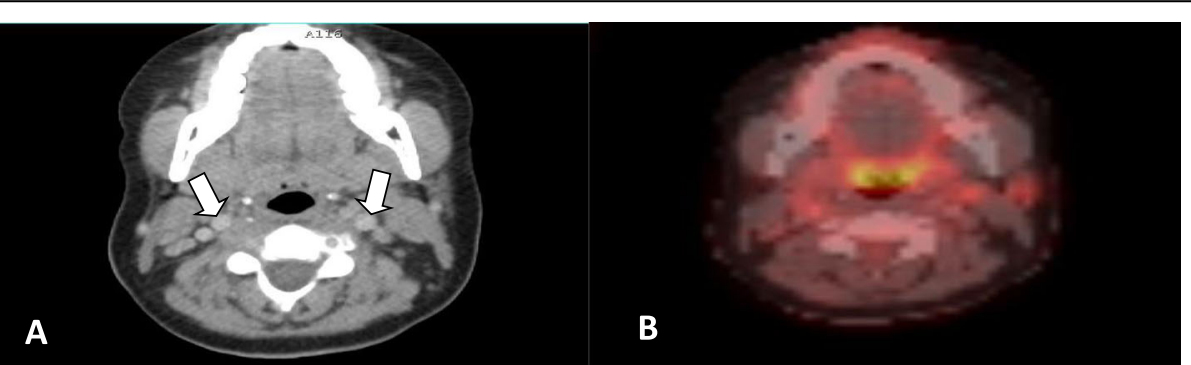

Fig. 6 Twenty-year-old patient, known case of treated Hodgkin lymphoma, finished chemotherapy. Few bilateral deep cervical LNs (a and b) of low grade metabolic activity are noted reaching up to 2.5 SUV max, mostly reactive in nature, consistent with a score of 1 on the five-point scale 

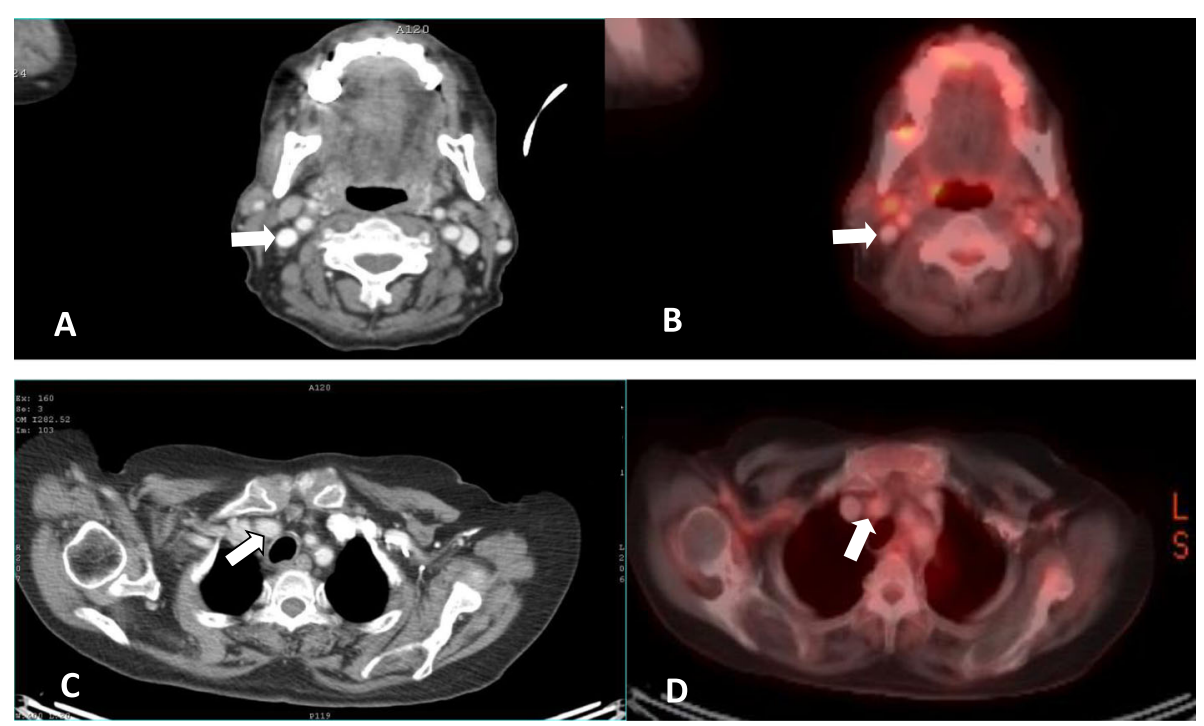

Fig. 7 Twenty-three-year-old patient, known case of Hodgkin lymphoma. Bilateral subcentimetric non FDG avid cervical LNs (a and b). Non FDG avid mediastinal LNs and thymic hyperplasia (c and $\mathbf{d}$ ) with low grade metabolic activity with SUV max 4.14, consistent with a score 2 on the five point scale

Zijlstra et al. [22] included 15 studies, involving 705 patients; all patients were for post treatment evaluation and residual masses; their sensitivity and specificity for detection of residual disease in nonHodgkin's lymphoma were $72 \%$ and $100 \%$, respectively; these results agree with current study as PET showed high sensitivity (100\%) and specificity (92\%) in prediction of disease recurrence; also, current study results agree with Lavely et al. [23] who studied 20 patients with non-Hodgkin's lymphoma after completion of therapy and they found that FDGPET prediction of relapse had sensitivity of $100 \%$ and a specificity of $84 \%$. Schaefer et al. [4] in a study of 66 patients with HL reported ranges for the sensitivity and specificity of PET-CT in predicting disease relapse with biopsy confirmation which were $100 \%$ and $91 \%$, respectively.

Table 4 Modified Deauville criteria of all studied patients

\begin{tabular}{lll}
\hline $\begin{array}{l}\text { Modified } \\
\text { Deauville } \\
\text { criteria }\end{array}$ & \multicolumn{2}{l}{ All studied patients $(\boldsymbol{n}=42)$} \\
\cline { 2 - 3 } & No. & $\%$ \\
\hline 1 & 12 & $28.5 \%$ \\
2 & 10 & $23.8 \%$ \\
3 & 3 & $7.1 \%$ \\
4 & 4 & $9.5 \%$ \\
$5 a$ & 5 & $11.9 \%$ \\
$5 b$ & 8 & $19 \%$ \\
\hline
\end{tabular}

Some previous reports [24, 25] (Table 5) provided the potential role of PET in detecting preclinical relapse but, on the other hand, showed the high false-positive rate, leading to unnecessary biopsies of FDG-avid lesions. Our findings are in line with those reported in literature [4, 16, 24-26], showing a sensitivity and a negative predictive value of $100 \%$, a positive predictive value of $54 \%$, and a false positive rate of $46 \%$. Limitations of our study include high cost and small number of patients. More studies are recommended with larger number of patients.

\section{Conclusion}

The lymphomas are a heterogeneous group of malignancies. PET-CT plays an important role in detection of response to treatment of lymphoma after finishing therapy.

Table 5 Prognostic values of PET scan of HL patients

\begin{tabular}{lllllll}
\hline Authors & $\begin{array}{l}\text { No. of } \\
\text { PET scans }\end{array}$ & HL pts & Rel/PET+ & $\begin{array}{l}\text { FP } \\
\text { rate }\end{array}$ & Spec & Sens \\
\hline Jerusalem et al. [16] & 119 & 36 & $5 / 11$ & $55 \%$ & $81 \%$ & $100 \%$ \\
Levine et al. [24] & 156 & 34 & $3 / 28$ & $89 \%$ & $84 \%$ & $100 \%$ \\
Meany et al. [25] & 57 & 23 & $2 / 11$ & $82 \%$ & $57 \%$ & $100 \%$ \\
Schaefer et al. [4] & NR & 66 & $23 / 27$ & $15 \%$ & $91 \%$ & $100 \%$ \\
Zinzani et al. [1, 26] & 605 & 160 & $51 / 164$ & $21 \%$ & $98 \%$ & $100 \%$ \\
Current study & 42 & 17 & $5 / 17$ & $70 \%$ & $92.3 \%$ & $100 \%$ \\
\hline
\end{tabular}




\section{Abbreviations}

BMT: Bone marrow transplantation; CMR: Complete metabolic response CTH: Chemotherapy; FDG: Fluorodeoxyglucose; HL: Hodgkin's lymphoma; MDCT: Multidetector computed tomography; NHL: Non-Hodgkin's lymphoma; PET-CT: Positron emission tomography-computed tomography PMR: Partial metabolic response; RTH: Radiotherapy; SUV max: Maximum standardized uptake value

\section{Acknowledgements}

Not applicable

\section{Authors' contributions}

$\mathrm{AL}$ and SS conceived and designed the analysis. SR collected the data, performed the analysis, and wrote the manuscript. All authors read and approved the final manuscript.

\section{Funding}

The authors state that this work has not received any funding.

\section{Availability of data and materials}

The datasets used and/or analyzed during the current study are available from the corresponding author on reasonable request.

\section{Ethics approval and consent to participate}

This study was approved by the ethical committee of Ain Shams University on June 2016 (no reference number was given at that time). All patients included in this study gave written informed consent to participate in this research by the patients themselves.

\section{Consent for publication}

Patients included in this research gave written informed consent to publish the data contained within this study.

\section{Competing interests}

The authors declare that they have no competing interests.

\section{Received: 24 January 2020 Accepted: 27 August 2020}

Published online: 08 September 2020

\section{References}

1. Zinzani PL, Tani M, Trisolini R et al (2007) Histological verification of positive positron emission tomography findings in the follow-up of patients with mediastinal lymphoma. Haematologica 92:771-777

2. Isasi CR, Lu P, Blaufox MD et al (2005) A meta-analysis of 18F-2-deoxy-2fluoro-D-glucose positron emission tomography in the staging and restaging of patients with lymphoma. Cancer 104:1066-1074

3. Rigacci L, Vitolo U, Nassi L et al (2007) Positron emission tomography in the staging of patients with Hodgkin's lymphoma. A prospective multicentric study by the Intergruppo Italiano Linfomi. Ann Hematol 86:897-903

4. Schaefer NG, Strobel K, Taverna C et al (2007) Bone involvement in patients with lymphoma: the role of FDG-PET/CT. Eur J Nucl Med 34:60-67

5. Hernandez-Maraver D, Hernandez-Navarro F, Gomez-Leon N et al (2006) Positron emission tomography/computed tomography: diagnostic accuracy in lymphoma. Br J Haematol 135:293-302

6. Gallamini A, Hutchings M, Rigacci L et al (2007) Early interim 2-(18F)fluoro-2deoxy-D-glucose positron emission tomography is prognostically superior to international prognostic score in advanced-stage Hodgkin's lymphoma: a report from a joint Italian-Danish study. J Clin Oncol 25:3746-3752

7. Hutchings $M$, Loft $A$, Hansen $M$ et al (2006) FDG-PET after two cycles of chemotherapy predicts treatment failure and progression-free survival in Hodgkin lymphoma. Blood 107:52-59

8. Haioun C, Itti E, Rahmouni E et al (2005) (18F) fluoro-2-deoxy-D-glucose positron emission tomography (FDG-PET) in aggressive lymphoma: an early prognostic tool for predicting patient outcome. Blood 106:1376-1381

9. Querellou S, Valette F, Bodet-Milin C et al (2006) FDG-PET/CT predicts outcome in patients with aggressive non-Hodgkin's lymphoma and Hodgkin's disease. Ann Hematol 85:759-767

10. Schot BW, Zijlstra JM, Sluiter WJ et al (2007) Early FDG-PET assessment in combination with clinical risk scores determines prognosis in relapsed lymphoma. Blood 109:486-491
11. Spaepen K, Stroobants S, Dupont P et al (2004) Prognostic value of positron emission tomography (PET) with fluorine-18 fluoro-deoxyglucose ([18F] FDG) after first-line chemotherapy in non-Hodgkin's lymphoma: is (18F)FDG PET a valid alternative to conventional diagnostic methods? J Clin Oncol 19: 414-419

12. Weihrauch MR, Re D, Scheidhauer $\mathrm{K}$ et al (2001) Thoracic positron emission tomography using 18F-fluorodeoxyglucose for the evaluation of residual mediastinal Hodgkin disease. Blood 98:2930-2934

13. Juweid ME, Stroobants S, Hoekstra O et al (2007) Use of positron emission tomography for response assessment of lymphoma: consensus of the imaging subcommittee of International Harmo-nization Project in lymphoma. J Clin Oncol 25:571-578

14. Kobe C, Dietlein M, Franklin J et al (2008) Positron emission tomography has a high negative predictive value for progression or early relapse for patients with residual disease after first-line chemotherapy in advancedstage Hodgkin lymphoma. Blood 112:3989-3994

15. Hutchings $M$, Loft $A$, Hansen $M$ et al (2007) Clinical impact of FDG-PET/CT in the planning of radiotherapy for early-stage Hodgkin lymphoma. Eur J Haematol 78:206-212

16. Jerusalem G, Beguin Y, Fassotte MF et al (2003) Early detection of relapse by whole-body positron emission tomography in the follow-up of patients with Hodgkin's disease. Ann Oncol:123-130

17. Johnson SA, Kumar A, Matasar MJ et al (2015) Imaging for staging and response assessment in lymphoma. Radiology 276(2):323-338

18. Bai C, Kinahan PE, Brasse D, Comtat C, Townsend DW, Meltzer CC et al (2003) An analytic study of the effects of attenuation on tumor detection in whole-body PET oncology imaging. J Nucl Med 44(11):1855-1861

19. Kostakoglu L, Cheson BD (2013) State-of-the-art research on "Iymphomas: role of molecular imaging for staging, prognostic evaluation, and treatment response". J Clin Oncol 3(212):1-9

20. Cheson BD, Fisher RI, Barrington SF et al (2014) Recommendations for initial evaluation, staging, and response assessment of Hodgkin and non-Hodgkin lymphoma: the Lugano classification. J Clin Oncol 32(27):3059-3068

21. Beal KP, Yeung HW, Yahalom J et al (2005) FDG-PET scanning for detection and staging of extranodal marginal zone lymphomas of the MALT type: a report of 42 cases. Ann Oncol 16(3):473-480

22. Zijlstra JM, Lindauer-van der Werf G, Hoekstra OS et al (2006) 18F- fluorodeoxyglucose positron emission tomography for posttreatment evaluation of malignant lymphoma: a systematic review. Haematologica 91:522-529

23. Lavely WC, Delbeke D, Greer JP, Morgan DS, Byrne DW, Price RR, Hallahan DE et al (2003) FDG PET in the follow-up management of patients with newly diagnosed Hodgkin and non-Hodgkin lymphoma after first-line chemotherapy. Int J Radiat Oncol Biol Phys 57(2):307-315

24. Levine JM, Weiner M, Kelly KM et al (2006) Routine use of PET scans after completion of therapy in pediatric Hodgkin disease results in a high false positive rate. J Pediatr Hematol Oncol 28:711-714

25. Meany HJ, Gidvani VK, Minniti CP et al (2007) Utility of PET scans to predict disease relapse in pediatric patients with Hodgkin lymphoma. Pediatr Blood Cancer 48:399-402

26. Zinzani PL, Stefoni $\mathrm{V}$, Tani M et al (2009) Role of [18F] fluorodeoxyglucose positron emission tomography scan in the follow-up of lymphoma. J Clin Oncol 27:1781-1787

\section{Publisher's Note}

Springer Nature remains neutral with regard to jurisdictional claims in published maps and institutional affiliations. 